\title{
SURFACE AND UNDERGROUND ULTRA LOW-LEVEL LIQUID SCINTILLATION SPECTROMETRY
}

\author{
Wolfango Plastino \\ Department of Physics, University of Roma Tre, via della Vasca Navale, 84, I-00146 Rome, Italy; also: INFN, Section of \\ Roma III, via della Vasca Navale, 84, I-00146 Rome, Italy. Corresponding author. Email: plastino@fis.uniroma3.it. \\ Lauri Kaihola \\ PerkinElmer Life and Analytical Sciences, Wallac Oy, P.O.B. 10, FIN-20101 Turku, Finland.
}

\begin{abstract}
Cosmic background and its variation have been removed in the Gran Sasso National Laboratory (National Institute of Nuclear Physics) by its 1400-m rock overburden. Stable, high-performance liquid scintillation counting conditions are obtained when any remaining variable components of the environmental background, such as radon, are eliminated. The ultra low-level liquid scintillation spectrometer Quantulus ${ }^{\mathrm{TM}}$ has an anti-Compton guard detector (guard for short) that allows monitoring of gamma radiation in the background. The guard detector efficiency in radiocarbon background reduction is $8 \%$ in the Gran Sasso National Laboratory, while $80 \%$ is observed in surface laboratories. Thus, atmospheric pressure variations in surface laboratories cause variation in cosmic radiation flux. The Quantulus anti-Compton detector is highly efficient in detecting cosmic radiation, and the sample count rate remains stable in long-term counting. Also, correlation of sample backgrounds with environmental gamma radiation in various laboratories is examined.
\end{abstract}

\section{INTRODUCTION}

Quantulus ${ }^{\mathrm{TM}}$ (PerkinElmer, Inc.) is an ultra low-level liquid scintillation spectrometer used in numerous radiocarbon laboratories for radiometric ${ }^{14} \mathrm{C}$ age determinations. Sample sizes down to a few hundred mg of carbon have been measured with various sample holder configurations (Haas 1979; Kalin and Long 1989; Hogg 1992; Kaihola et al. 1992; Buzinny and Skripkin 1995) which give lower backgrounds than larger vials.

The basic Quantulus design follows the conventional LSC configuration of 2 photomultiplier tubes (PMTs) to monitor the sample. Only coincidence events are accepted in beta counting; thus, most phototube random thermal noise is rejected. At the same time, tritium counting efficiency is maintained when compared to single phototube systems, where a threshold has to be applied to improve the signal to noise ratio. The typical single photon noise figure is $0.15 \mathrm{CPM}$ and resides in the first 100 channels of the logarithmic energy scale, which are normally discarded with small ${ }^{14} \mathrm{C}$ counting efficiency loss by applying a high bias threshold. A background reduction by a factor of 50 in the full 2-MeV beta energy window is achieved by using a passive low radioactivity Boliden lead shield with a mass of $640 \mathrm{~kg}$. Its shape is optimized with up to $20 \mathrm{~cm}$ thickness towards the zenith, from which most of the muon flux comes.

The counting chamber is inside an active anti-Compton guard detector made of OFHC copper filled with mineral oil scintillation cocktail. It is asymmetric with a larger volume on top of the sample. The guard has 2 phototubes working in conjunction which detect a fraction of the inherent tube radioactivity. The guard is a true cosmic event detector with no optical contact with the sample. Its performance does not, therefore, depend on the sample matrix, as in designs where a single phototube pair is used for both the sample and guard. Previously, the Quantulus guard used cadmium lining to remove the thermal neutron flux. This has been changed (due to health hazard reasons and non-observable background reduction) to copper lining, which together with guard copper walls, attenuates $\mathrm{Pb}$ X-rays generated by the small ${ }^{210} \mathrm{~Pb}$ contamination in lead. The sample is lifted into the counting chamber with a massive copper piston that acts as a passive shield downwards. The

(C) 2004 by the Arizona Board of Regents on behalf of the University of Arizona Proceedings of the 18th International Radiocarbon Conference, edited by N Beavan Athfield and R J Sparks RADIOCARBON, Vol 46, Nr 1, 2004, p 97-104 
anti-Compton guard further reduces the full window background by a factor of 5 . It detects cosmic muons to almost $100 \%$, which can be verified by recording rejected sample events (spectrum 12 in ${ }^{14} \mathrm{C}$ counting mode) in high channels (channel 850 and upwards).

The low radioactivity sample phototubes are matched pairs with low thermal noise. The tube window is made of silica and its walls are built from short cylinders of graded glass to connect to Pyrex glass at the anode. Sample and guard phototubes are the radioactive components close to the sample chamber.

The multichannel analyzer collects up to 4 simultaneous spectra by Boolean logic control (Polach et al. 1984). Rejected events may be recorded and this feature is used below to estimate guard detector efficiency.

\section{LOW-BACKGROUND LABORATORIES FOR LIQUID SCINTILLATION COUNTING}

There are numerous laboratories using Quantulus, either underground or built from low-activity materials, to reduce environmental background radiation. BVFA Arsenal in Vienna (Aiginger et al. 1986) has $1.6 \mathrm{~m}$ of concrete, $0.6 \mathrm{~cm}$ of steel, and 3-cm lead linings and the positive pressure of filtered air. The reduction of gamma flux is 1:20 as in the Wallac low-level laboratory (Kaihola et al. 1986). The latter has $0.5 \mathrm{~m}$ of low-activity concrete and $0.5 \mathrm{~m}$ of normal concrete outside the first layer. The room is a Faraday cage and in overpressure of filtered air to remove radon. The University of Arizona Radiocarbon Laboratory in Tucson, Arizona, has an underground laboratory with 5 Quantuluses which have a $10-\mathrm{m}$ overburden at $15{ }^{\circ} \mathrm{C}$ (Kalin and Long 1989). The instrument temperatures for ${ }^{14} \mathrm{C}$ dating are kept close to the benzene freezing point at $7{ }^{\circ} \mathrm{C}$. The VKTA Rossendorf laboratory in Dresden is built in an old wine cellar with carefully selected construction materials and $47 \mathrm{~m}$ of rock ( $110 \mathrm{~m}$ water equivalent) above, which blocks $98 \%$ of the cosmic muon flux (Niese et al. 1998). The Gran Sasso National Laboratory (National Institute of Nuclear Physics) has the most overburden of rock for labs where any Quantuluses have resided so far. It has a depth of $1400 \mathrm{~m}$, equivalent to $3800 \mathrm{~m}$ of water (Plastino et al. 2001), which reduces the cosmic flux to 1 millionth of the surface value.

\section{BACKGROUND REDUCTION IN QUANTULUS}

Phototubes contain some ${ }^{40} \mathrm{~K}$ and Cerenkov radiation produced in the envelope by $1.3-\mathrm{MeV}$ beta particles ( $89 \%$ of all decays). This radiation can also channel into the other phototube and these cross-talk events may be detected as coincidences. Similarly, there is fluorescence from glass with longer pulse length, and these events can be separated by pulse shape analysis (Kaihola 1991). Cross-talk events can be rejected by the pulse amplitude comparator (PAC), which is controlled by software to exclude events in high left/right signal amplitude disparity. This method always leads to some loss of ${ }^{14} \mathrm{C}$ signal and should be avoided for high-quench samples and for ${ }^{3} \mathrm{H}$, because the number of photons from such a decay event is very low. The amplitude disparity is high in such cases and application of the PAC would cause serious efficiency loss. The PAC has been tuned to have a milder effect in the low-energy region in order not to distort the sample spectrum. Cross-talk events can also be rejected by special vial designs, where unused volume is replaced by a massive, non-transparent cap and base (copper-teflon vial by Wallac; Polach et al. 1983). This design leads to a linear dependency of sample background on its volume (Kaihola et al. 1992).

\section{ATMOSPHERIC PRESSURE EFFECTS}

Atmospheric pressure variation has an observable effect on the anti-Compton guard detector count rate (Figure 1). The cosmic muon flux is lower during a high-pressure period (Figure 2). The Comp- 
ton electron spectrum of the environmental and inherent gamma background also has an additional, variable cosmic component (Figure 3).

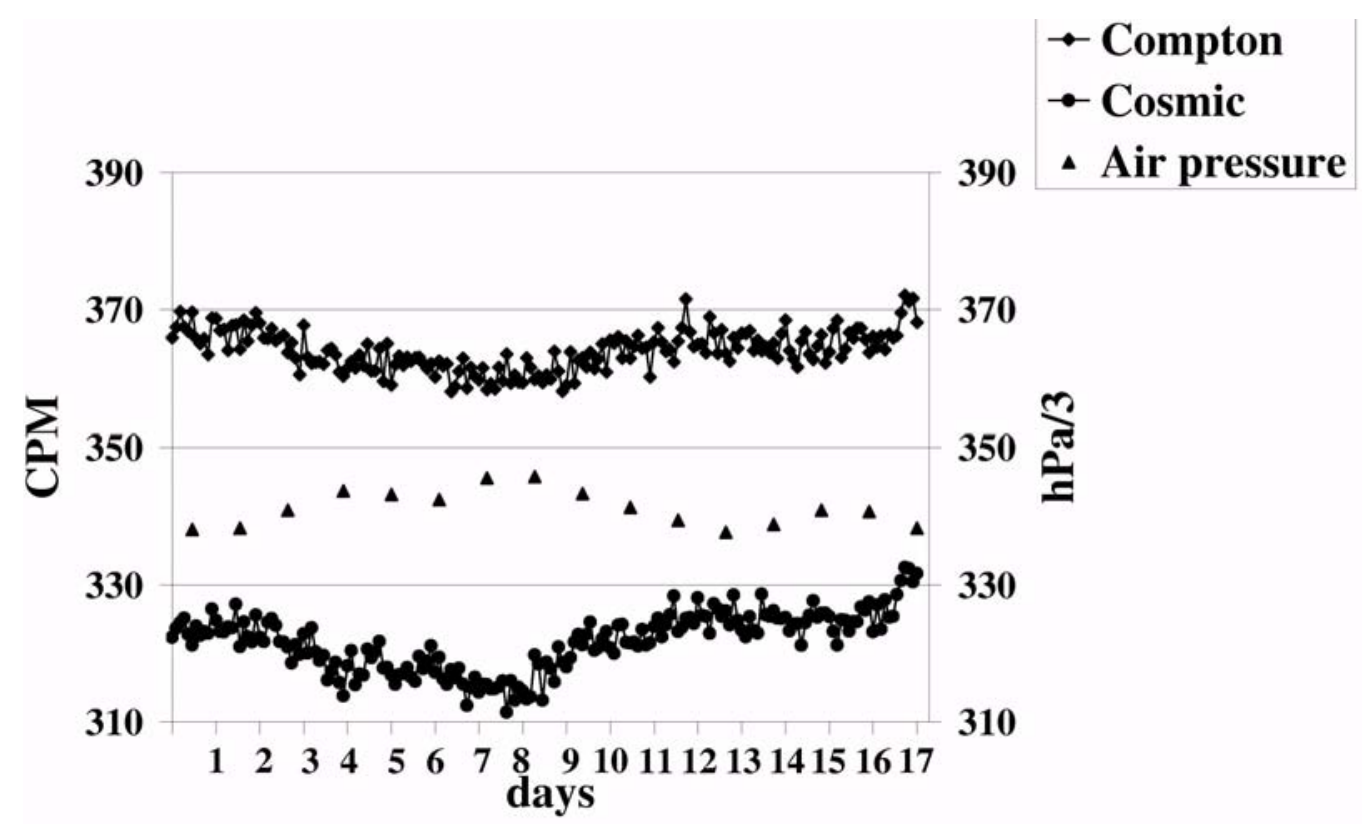

Figure 1 Guard Compton electron and muon peak count rate variation with air pressure on the surface (Wallac lowlevel laboratory) for 17 days. Air pressure reading (hPa) has been divided by 3 to scale down.

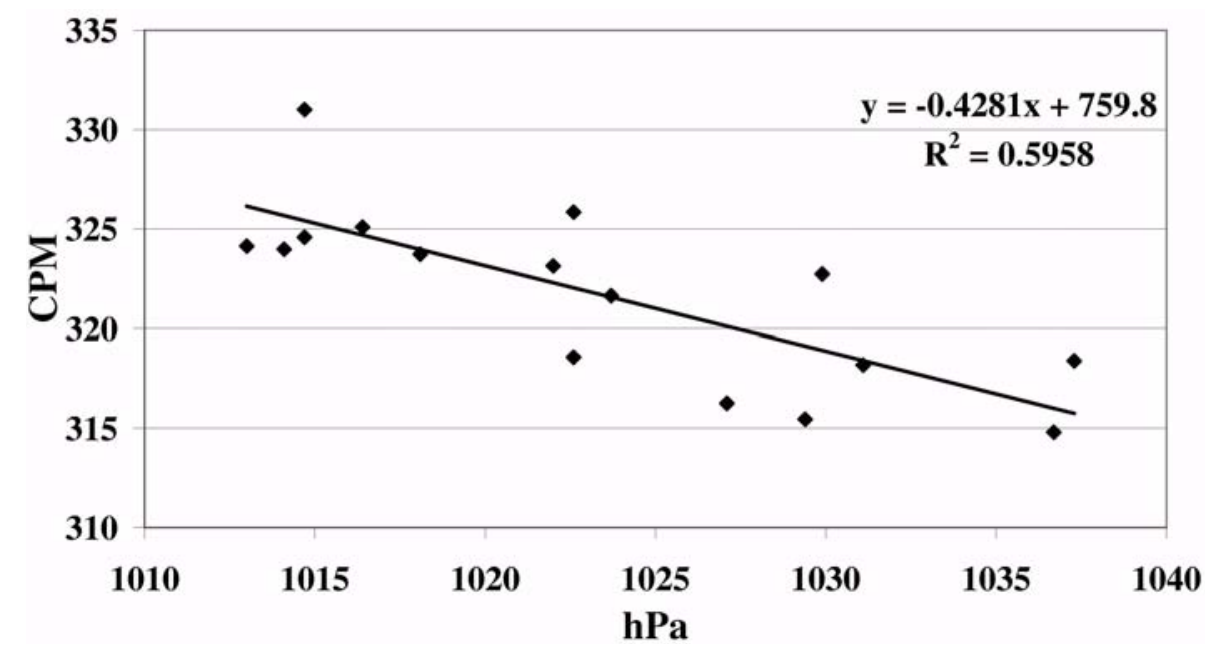

Figure 2 Guard muon count rate versus atmospheric pressure

The guard efficiency is calculated in the sample spectrum energy range, i.e., by the fraction of sample counts coincident with the guard to the total sample count rate. In the ${ }^{14} \mathrm{C}$ counting mode, with the pulse amplitude comparator, $\mathrm{PAC}=1$ (inactive), as in the following:

$$
\text { Guard efficiency }=100 \times \text { SP12/(SP11+SP12), }
$$




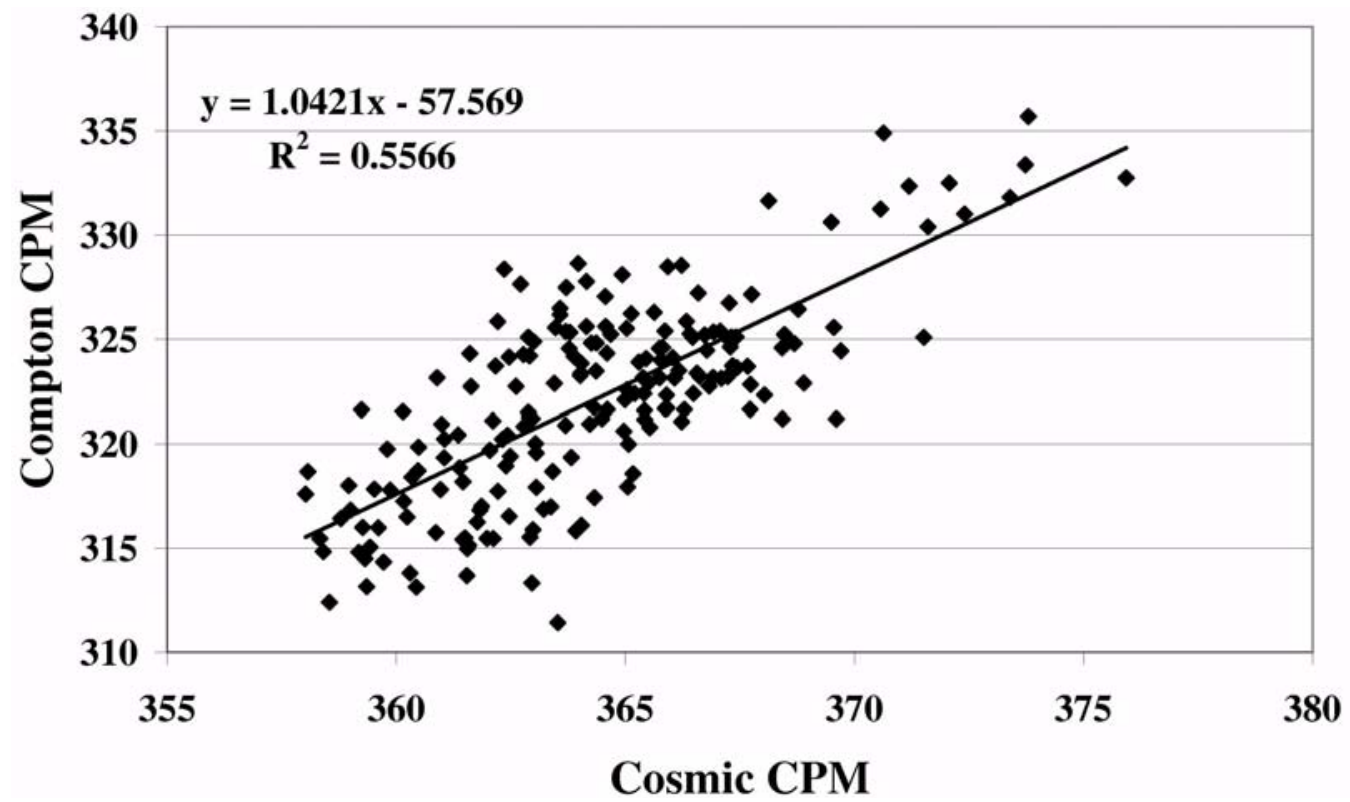

Figure 3 Compton count rate versus cosmic muon count rate under variable air pressure for 17 days

where SP12 is the guard rejected or coincidence counts and SP11 is the net accepted or anticoincidence counts. Efficiency is given as a removed fraction of background water sample events on the surface (Figure 4) and in the underground laboratory (Figure 5).

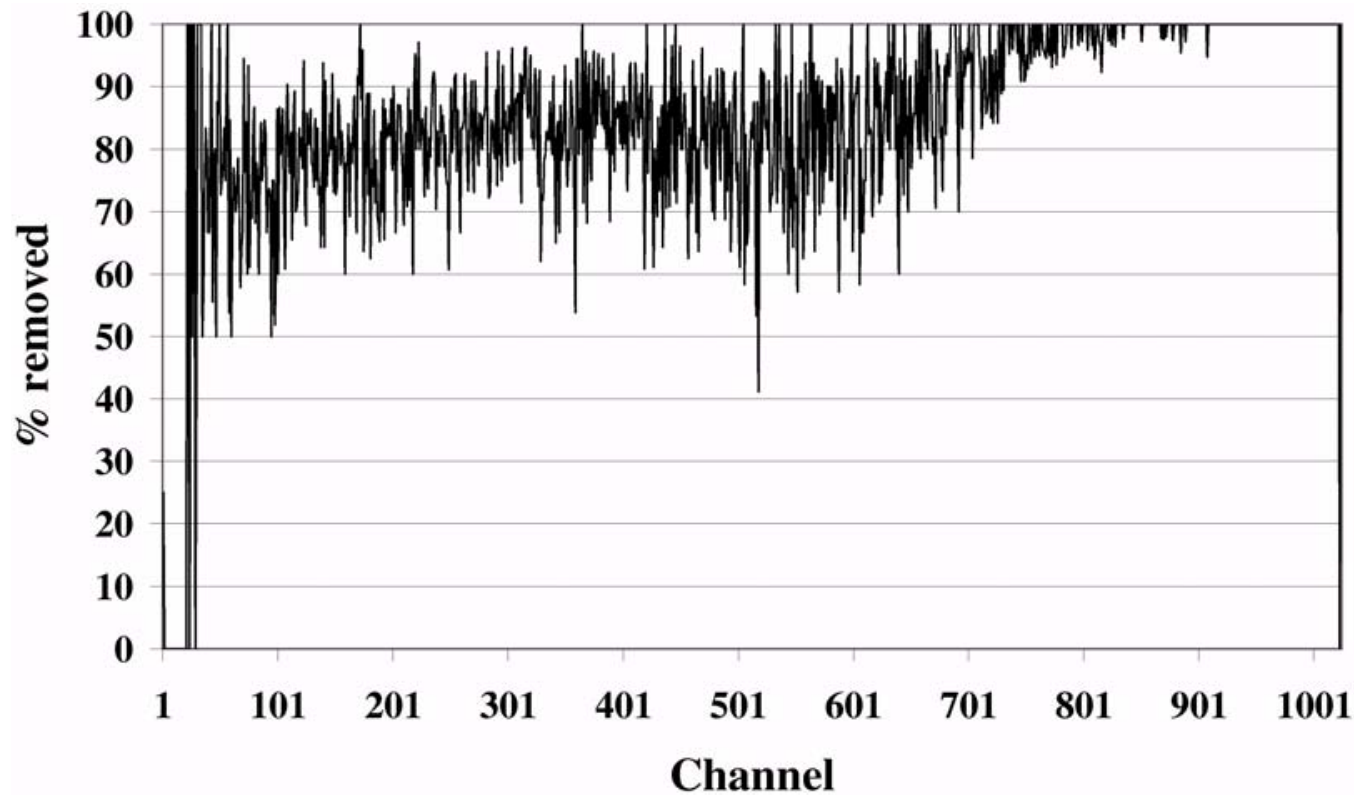

Figure 4 Guard efficiency in $6 \mathrm{~mL}$ water:9 $\mathrm{mL}$ OptiPhase HiSafe 3, measured in Wallac production hall 


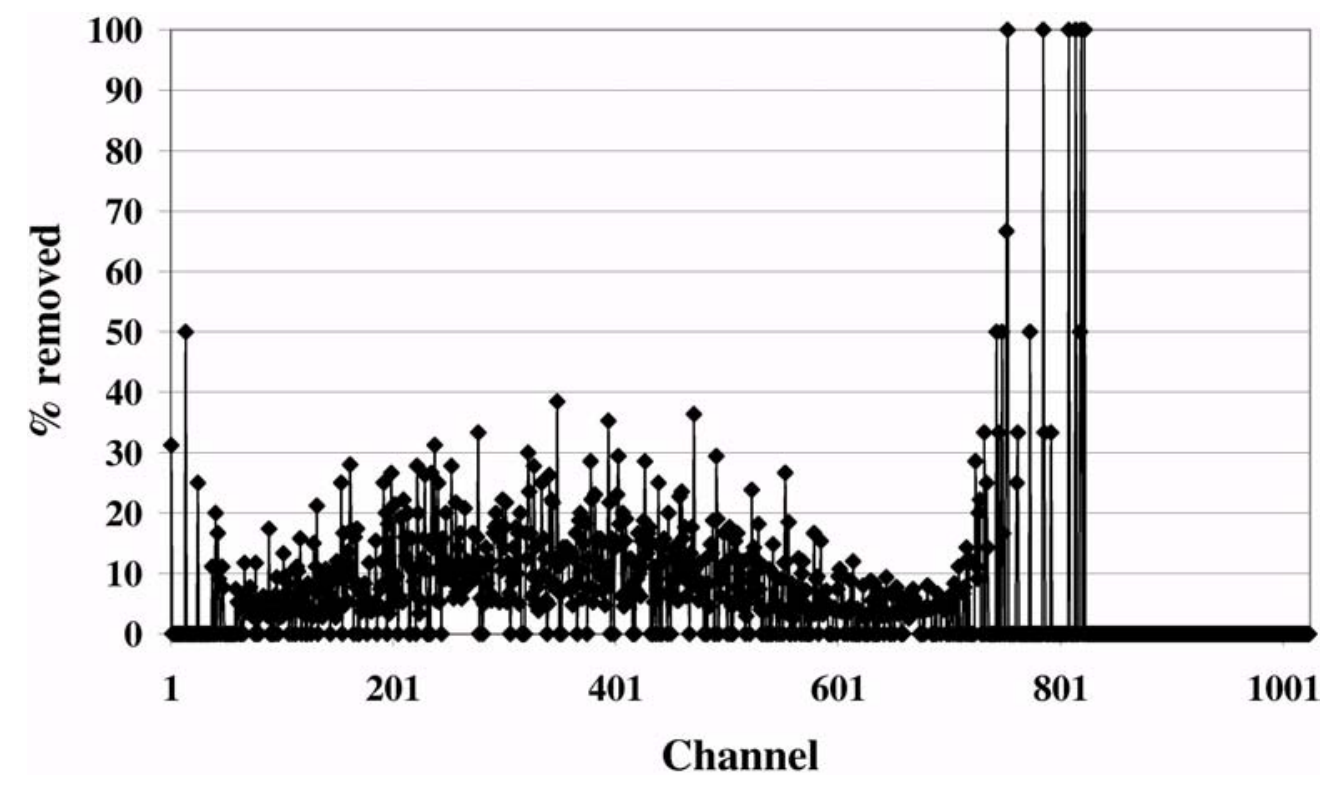

Figure 5 Guard efficiency in the Gran Sasso National Laboratory measured with a water sample, $8 \mathrm{~mL}: 12 \mathrm{~mL}$ (water: Ultima Gold LLT)

The guard efficiency in cosmic muon channels $750-1024$ is $99.0 \%$ on the surface. The full sample window (Ch $1-1024$ ) efficiency is $86.9 \%$, and in Ch $1-749$ the efficiency is $82.3 \%$.

In underground measurements, the efficiency is given as $100 \%$ above channels 750 , if no counts were recorded. The mean guard efficiency in Compton channels $1-750$ is $7.6 \%$.

The drop of guard efficiency below $80 \%$ ( $\mathrm{PAC}=1$ or inactive in ${ }^{14} \mathrm{C}$ counting mode) always means some extra activity in the vial, in the sample (which also includes cocktail) (Kaihola 1993), and/or in the counting chamber (contamination or radon). The drop is also observed in the case of the absence of cosmic radiation, when inherent sample phototube activity is a greater proportion of total background and remains undetected in the Gran Sasso lab.

\section{BACKGROUND DEPENDENCE ON ENVIRONMENTAL GAMMA RADIATION}

The sample background varies with environmental gamma background. It is possible to give an estimate of the expected ${ }^{14} \mathrm{C}$ background when the guard Compton continuum count rate is known (Figure 6).

Sample background variations between laboratories are due to different environmental gamma fluxes in each laboratory. Backgrounds are stable in each individual laboratory when the environmental conditions remain steady.

\section{VOLUME DEPENDENCE OF SAMPLE BACKGROUND}

Special vial designs eliminate cross-talk events, as in copper-teflon vials by Wallac where unused volume is replaced by a massive, non-transparent cap and base (Polach et al. 1983). This masked vial design leads to linear dependency of sample ${ }^{14} \mathrm{C}$ background on its volume. Figure 7 shows a graph (other surface labs) down to $0.3-\mathrm{mL}$ masked vial size, with extrapolated 0.05 -CPM empty vial 


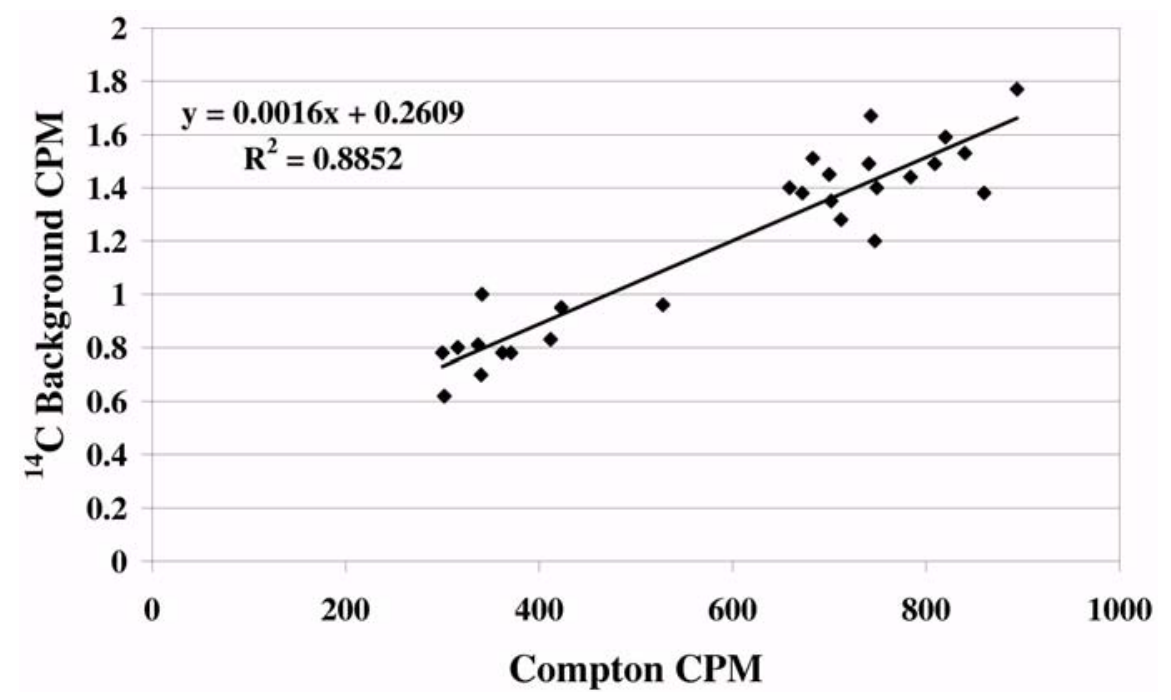

Figure 6 Background count rate in optimum ${ }^{14} \mathrm{C}$ window versus guard Compton rate in 15 -mL copperteflon vials in 27 laboratories. Sample is benzene with $15 \mathrm{mg} / \mathrm{mL}$ butyl-PBD as scintillant.

background (Kaihola et al. 1992). When a large 9-mL teflon vial is used for variable volumes, background dependence is again linear, but additional contribution remains due to the unfilled empty volume, which is a source of air scintillations (Kaihola 1996). The surface laboratory (Bologna) has extrapolated a 0.26-CPM background at zero benzene volume in a 9-mL unmasked vial, while underground (Gran Sasso) it is 0.04 CPM (Plastino et al. 2001).

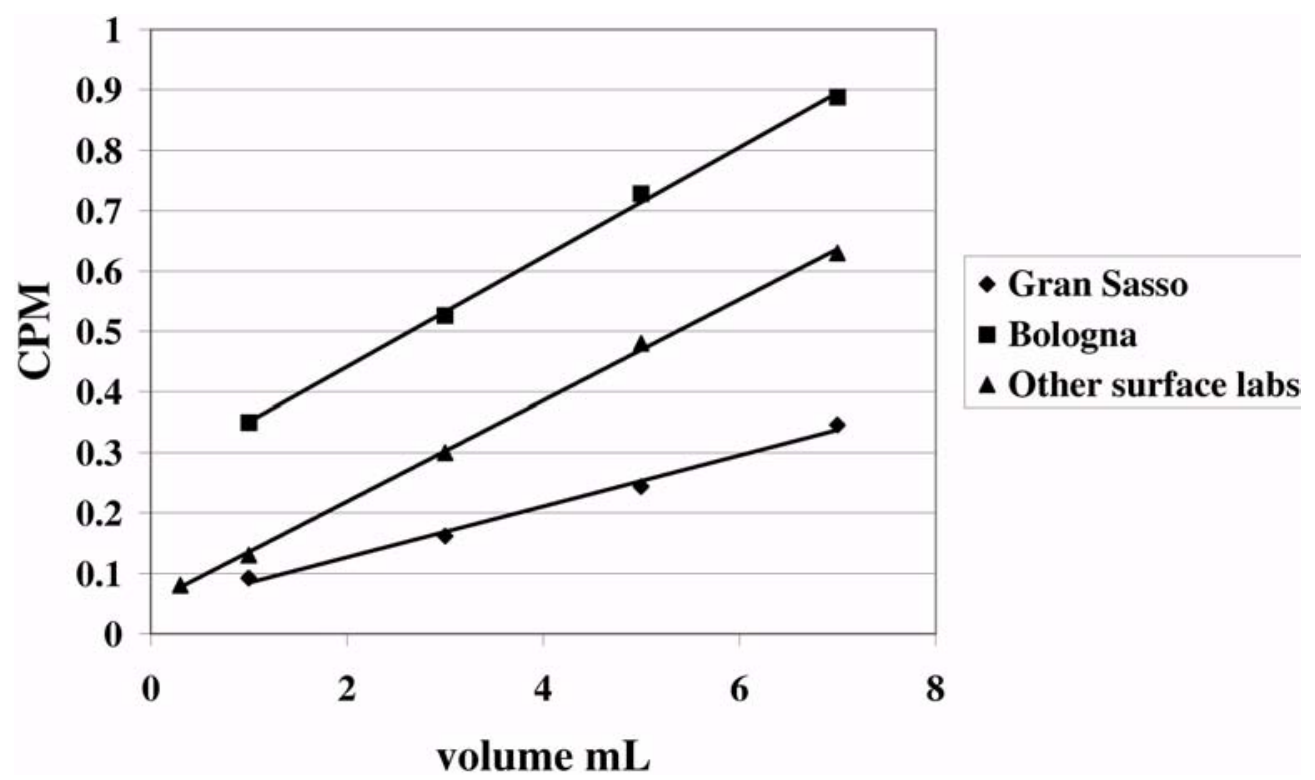

Figure 7 Background dependence on benzene volume in Gran Sasso National Laboratory, 9-mL unmasked teflon vial $(\mathrm{CPM}=0.0422 \times \mathrm{V}+0.0422)$; Radiocarbon Laboratory ENEA-Bologna, 9-mL teflon vial $(\mathrm{CPM}=0.0908 \times \mathrm{V}+0.2598)$; other surface laboratories, 3-, 7-, 15-, and 20-mL masked copper-teflon vials and $0.3-\mathrm{mL}$ teflon vial in a black masking Delrin adapter $(\mathrm{CPM}=0.0844 \times \mathrm{V}+0.0507)$. 
The masked vial filled with benzene approaches the same zero volume background on the surface as an unmasked vial with equivalent benzene volumes underground in Gran Sasso. Absolute background figures in Gran Sasso are about a half of the surface figures of the ideal masked vials.

\section{DISCUSSION}

The Quantulus is well equipped with various background reduction devices. Background variation due to atmospheric pressure effects is resolved by these devices. However, the most important factor is to have a clean counting environment with no additional background variations in gamma flux. Radon concentration should be kept very low $\left(<10 \mathrm{~Bq} / \mathrm{m}^{3}\right)$ and constant. Access of sunlight to the sample preparation area and counting room should be prevented; incandescent lighting is always better for such rooms than fluorescent lighting. Samples stabilize in about $4 \mathrm{hr}$ to the instrument temperature and chemiluminescence decays at the same time.

Since the cosmic flux is negligible in the Gran Sasso laboratory, we can attribute the sample background to be fully derivable from the instrument's internal and external gamma radiation. The gamma flux in the laboratory is not negligible and radon is present in the water that flows into the laboratory (Plastino and Bella 2001). The laboratory is well ventilated and stable in temperature $\left(9{ }^{\circ} \mathrm{C}\right)$; therefore, no cooling unit is used in the Quantulus. The instrument is placed in a steel container, which is a good Faraday cage and also shields from radon.

The guard Compton continuum, channels 50 to 850 , comes from the phototubes, the environmental gamma scattering, and from secondary cosmic interactions. The latter is missing in Gran Sasso and is very small on the surface, while the environmental gamma scattering is constant. Thus, the variation of the Compton continuum reflects the environmental radioactivity of the laboratory and can be correlated with instrument performance in sample counting.

\section{CONCLUSIONS}

Atmospheric pressure variations cause both cosmic flux variations. The guard is, however, so efficient for high-energy cosmic radiation that the variation does not show as a sample signal. The guard count rate is opposite the air pressure phase.

The big difference in the guard detector efficiency between surface laboratories and underground laboratories such as Gran Sasso is related to the absence of cosmic and associated lower energy Compton radiation. The inherent radioactivity of phototubes is a larger fraction of the total background signal in Gran Sasso. The role of radon remains to be examined in an environment where its presence is eliminated.

Masked vials approach the same zero volume background on the surface as an unmasked vial in the Gran Sasso National Laboratory, where absolute backgrounds are about a half of the surface figures.

\section{ACKNOWLEDGEMENTS}

We wish to thank Prof Eugenio Coccia, Director of Gran Sasso National Laboratory, for his kind collaboration. The work was funded by EU-LNGS (INFN) (HPRI-CT-2001-00149)-LNGS (INFN)-

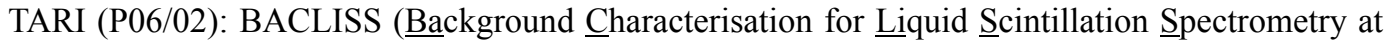
the underground laboratory of Gran Sasso). 


\section{REFERENCES}

Aiginger H, Maringer FJ, Rank D, Unfried E. 1986. A new laboratory for routine low-level measurements (BVFA Arsenal, Wien). Nuclear Instruments and Methods in Physics Research B 17:435-7.

Buzinny M, Skripkin V. 1995. Newly designed 0.8-mL teflon vial for micro-volume radiocarbon dating. $R a-$ diocarbon 37(2):743-7.

Haas H. 1979. Specific problems with liquid scintillation counting of small benzene volumes and background count rates estimation. In: Berger R, Suess HE, editors. Radiocarbon Dating. Berkeley: University of California Press. p 246-55.

Hogg A. 1992. Assessment of 0.3-mL minivials for radiocarbon dating by liquid scintillation counting of benzene. Radiocarbon 34(3):389-93.

Kaihola L, Kojola H, Kananen R. 1986. Low-level liquid scintillation counter performance in a low-level surface laboratory. Nuclear Instruments and Methods in Physics Research B 17:509-10.

Kaihola L. 1991. Liquid scintillation counting performance using glass vials in the Wallac 1220 Quantulus. In: Ross H, Noakes JE, Spaulding JD, editors. Liquid Scintillation Counting and Organic Scintillators. Chelsea: Lewis Publishers. p 495-500.

Kaihola L, Kojola H, Heinonen A. 1992. A minivial for small sample ${ }^{14} \mathrm{C}$ dating. Radiocarbon 34(3):402-5.

Kaihola L. 1993. Glass vial background reduction in liquid scintillation counting. The Science of the Total Environment 130/131:297-304.
Kaihola L. 1996. Direct detection of radon gas in air using a liquid scintillation counter. In: Technologically Enhanced Natural Radiation by Non-Uranium Mining. Katowice: Central Mining Institute. p 169-75.

Kalin RM, Long A. 1989. Radiocarbon dating with the Quantulus in an underground counting laboratory: performance and background sources. Radiocarbon 31(3):359-67.

Niese S, Köhler M, Gleisberg B. 1998. Low-level-counting techniques in the underground laboratory "Felsenkeller" in Dresden. Journal of Radioanalytical and Nuclear Chemistry 233(1-2):167-72.

Plastino W, Bella F. 2001. Radon groundwater monitoring at underground laboratories of Gran Sasso (Italy). Geophysical Research Letters 28(14):2675-78.

Plastino W, Kaihola L, Bartolomei P, Bella F. 2001. Cosmic background reduction in the radiocarbon measurement by liquid scintillation spectrometry at the underground laboratory of Gran Sasso. Radiocarbon 43(2A):157-61.

Polach H, Gover J, Kojola H, Heinonen A. 1983. An ideal vial and cocktail for low-level scintillation counting: copper-shielded PTFE (Teflon) and butylPBD. In: McQuarrie SA, Ediss C, Wiebe LI, editors. Advances in Scintillation Counting. Edmonton: University of Alberta Press. p 508-25.

Polach H, Kojola H, Nurmi J, Soini E. 1984. Multiparameter liquid scintillation spectrometry. Nuclear Instruments and Methods in Physics Research B 5:439-42. 